\title{
INVESTIMENTO DIRETO EXTERNO E INDUSTRIALIZAÇÃO NO BRASIL*
}

\author{
Marcelo Curado
}

\section{Marcio José Vargas da Cruz ${ }^{* * *}$}

RESUMO Este artigo tem como objetivo discutir o papel do investimento direto externo - IDE no processo de industrialização da economia brasileira entre 1860 e 1980. Utiliza-se como referência de periodização desse processo a proposta elaborada por Tavares (1975) e Mello (1982), que apresenta a seguinte configuração: (1) Crescimento com diversificação da atividade industrial (1860-1933); (2) Industrialização restringida (1933-1955); e (3) Industrialização pesada (1955-1980). A análise demonstra que o comportamento dos IDEs deve ser entendido à luz das condições vigentes no plano interno e externo, como proposto originalmente por Possas (1983).

Palavras-chave: investimento estrangeiro direto; industrialização; economia brasileira

Código JEL: N 66 - economic history; manufacturing and construction; Latin America; Caribbean

\section{FOREIGN DIRECT INVESTMENT AND INDUSTRIALIZATION IN BRAZIL}

ABSTRACT This paper analyses the role of the foreign direct investment - FDI, in the industrialization process of Brazilian economy between 1860 and 1980. The reference for the division the period was the proposal by Tavares (1975) and Mello (1982): Growth with industrial activity diversification (1860-1933); Restrict indus-

* Artigo recebido em 13 de agosto de 2007 e aprovado em 23 de outubro de 2008.

** Professor do Departamento de Economia da Universidade Federal do Paraná. Doutor em Economia pela Unicamp, e-mail: mcurado@ufpr.br

*** Professor do Departamento de Economia da Universidade Federal do Paraná. Mestre em Desenvolvimento Econômico pelo PPGDE-UFPR, e-mail: marciocruz@ufpr.br 
trialization (1933-1955) and 3. Heavy industrialization (1955-1980). The research demonstrate that to comprehend the behavior of the FDI, it's necessary to considerate the domestic and foreign conditions, as the proposal by Possas (1983).

Key words: foreign direct investment; industrialization; brazilian economy 


\section{INTRODUÇÃO}

O objetivo deste artigo é discutir o papel do IDE no processo de industrialização da economia brasileira para o longo período compreendido entre 1860 e 1980. Utiliza-se como referência de periodização desse processo a proposta elaborada por Tavares (1975) e Mello (1982), que apresenta a seguinte configuração:

(1) crescimento com diversificação da atividade industrial (1860-1933);

(2) industrialização restringida (1933-1955); e

(3) industrialização pesada (1955-1980).

Os movimentos do capital produtivo internacional são analisados a partir da proposta de interpretação elaborada por Possas (1983). De acordo com autor, os movimentos do capital produtivo devem ser entendidos como resultantes da conjunção das condições vigentes na economia internacional e das condições internas de acumulação. A discussão sobre o papel dos IDEs no processo de industrialização é muito vasta, o que torna necessária a focalização da análise em algumas variáveis. Nesse sentido, este artigo concentra a análise do comportamento do capital produtivo no Brasil ao longo do período estudado em três variáveis centrais:

(1) o volume dos investimentos;

(2) a concentração setorial; e

(3) a origem de propriedade do capital.

A principal contribuição do trabalho é apresentar, de forma sintética, a evolução do comportamento do capital produtivo no Brasil para um longo período de análise (1860-1980), demonstrando que esse comportamento deve ser entendido à luz das condições vigentes no plano interno e externo, como proposto originalmente por Possas (1983).

O trabalho encontra-se organizado da seguinte forma. Além desta breve introdução, realiza-se na seção 1 uma breve revisão da literatura acerca dos determinantes do IDE. A seção 2 apresenta uma discussão sobre a periodização do processo de industrialização utilizado. A seção 3 discute o IDE na fase de crescimento com diversificação da atividade industrial. A discussão do papel do IDE no contexto da industrialização restringida é realizada na seção 4. A seção 5 aborda a importância do IDE na fase da industrialização pesada da economia brasileira. A seção 6 apresenta algumas breves conclusões do trabalho. 


\section{DETERMINANTES DO INVESTIMENTO DIRETO EXTERNO: UMA BREVE REVISÃO DA LITERATURA}

O objetivo desta seção é realizar uma breve revisão da literatura econômica que estuda os determinantes dos movimentos do capital produtivo. A amplitude da literatura torna esta resenha limitada a um conjunto de trabalhos selecionados e é reconhecidamente incompleta. ${ }^{1}$ Serão analisadas as contribuições de Hymer (1976) e a teoria do poder de mercado, a teoria da internalização das firmas, o paradigma eclético de Dunning (1979), as contribuições teóricas associadas à competição internacional intra-indústria, os recentes desenvolvimentos da macroeconomia e, finalmente, mas não menos importante, a proposta de análise metodológica apresentada por Possas (1983).

Hymer (1976) parte da hipótese, muitas vezes utilizada pela literatura de organização industrial do período, de que existe uma tendência à formação de estruturas de mercado do tipo oligopólica derivada dos processos de acordo/colusão entre firmas que possuam a priori alguma vantagem competitiva em relação a suas concorrentes no mercado local. No entanto, esse processo de oligopolização, que garante a obtenção de uma taxa de lucro supranormal, encontra limites na economia local, sendo o processo de internacionalização da produção uma das formas de superação dessa limitação. De acordo com Cantwell (1990), esse movimento para fora das firmas pode inclusive ser acelerado pela retração do crescimento do mercado doméstico, que resulta da diminuição dos incentivos ao investimento em um contexto de elevação do poder de mercado das firmas.

Em suma, de acordo com Hymer (1976), o processo de internacionalização é motivado pelos limites impostos pelas dimensões do mercado local às firmas oligopolistas, o que em última instância se traduz em limites impostos à obtenção/manutenção de lucros supranormais. A internacionalização da produção é uma decisão interna à firma motivada, conforme exposto, pelo limite ao processo de oligopolização imposto pela dimensão restrita do mercado local.

A teoria da internalização da firma baseada nos trabalhos originais de Coase (1937) é também utilizada para explicar o processo de internacionalização produtiva. Hennart (1990), por exemplo, argumenta que esse pro- 
cesso de internacionalização decorre dos custos de transação existentes na presença de falhas de mercado. A transnacionalização da firma ocorrerá quando o custo de organização de determinada transação econômica via mercado for superior ao custo de internalização. A questão central da teoria da internalização encontra-se, portanto, no ganho de eficiência que o processo de internacionalização da produção irá gerar vis-à-vis a manutenção de transações via mercado. Nesse sentido, a presença das vantagens competitivas enfatizadas por Hymer (1976) é necessária, porém insuficiente para explicar os movimentos do capital produtivo em nível internacional.

Dunning (1979) defende a necessidade de explicar os padrões de internacionalização produtiva através da construção de um "paradigma eclético", entendido como uma proposta metodológica de união de diversas abordagens teóricas, em particular a teoria do poder de mercado de Hymer (1976), a teoria da internalização e de uma teoria da localização. Objetivamente, a firma irá se engajar na internacionalização de suas atividades caso três condições sejam satisfeitas:

(1) as firmas devem possuir vantagens monopolísticas vis-à-vis as firmas de outros países, tal como proposto por Hymer (1976);

(2) assumindo satisfeita a condição 1, deve ser benéfico para a empresa que possua tais vantagens internalizá-las através da extensão de suas próprias atividades, em vez de externalizá-las licenciando ou realizando transações via mercado, elemento diretamente derivado da teoria da internalização; e

(3) assumindo 1 e 2 satisfeitas, deve ser mais lucrativo para a empresa utilizar essas vantagens em conjunção com fatores externos ao seu país.

A construção do "paradigma eclético" tem a vantagem de reunir as principais abordagens teóricas sobre os determinantes dos movimentos do capital produtivo, fornecendo, em alguma medida, uma unidade a esse conjunto de contribuições sem precedentes na literatura sobre o tema e que as tornam leitura essencial para os pesquisadores da área.

Cantwell (1990) organiza ainda um outro conjunto de contribuições sobre o tema da internacionalização da produção. Duas áreas merecem destaque, de acordo com o autor:

(1) a análise da competição intra-indústria em nível internacional; e 
(2) as contribuições derivadas dos desenvolvimentos da macroeconomia.

No que se refere ao primeiro grupo, o autor destaca a ampliação do número de trabalhos que incorporam a questão da competição tecnológica como determinante do processo de internacionalização produtiva. Esse processo, sobretudo entre países desenvolvidos, deve ser entendido como fruto da capacitação tecnológica da qual as empresas multinacionais são capazes de apropriar-se em função da existência de "extravazamentos" do sistema. Assim, por exemplo, quanto maior o grau de desenvolvimento dos centros de pesquisa e mais aperfeiçoado o sistema educacional, maior a atratividade do país para o capital produtivo internacional.

Ainda seguindo o trabalho de Cantwell (1990), merecem ser destacadas algumas contribuições derivadas dos desenvolvimentos da macroeconomia para o entendimento dos movimentos do capital produtivo em nível internacional. Merece destaque, ainda segundo o autor, os trabalhos de Vernon (1966) e o modelo de Kojima e Osawa (1985).

A contribuição de Vernon (1966) está diretamente relacionada à interpretação dos movimentos iniciais das empresas norte-americanas em direção à Europa. De acordo com o trabalho, os elevados níveis de renda e de demanda nos Estados Unidos promoveram um movimento de inovações, especialmente nos setores de bens de consumo duráveis com técnicas labour intensive. Essa vantagem monopolística foi inicialmente explorada através de exportações. Porém, o amadurecimento dos produtos e o processo de catching up tecnológico conduzido pelos países da Europa reduziram significativamente a vantagem competitiva das empresas norte-americanas que passam, em função dos custos com transportes e das barreiras tarifárias, a transnacionalizar suas atividades produtivas. O processo de transnacionalização em direção à periferia seria, ainda de acordo com o trabalho, fruto da maturação de produtos e de processos produtivos e da ampliação da competição via preços no mercado internacional.

O modelo de Kojima e Osawa (1985) parte das hipóteses neoclássicas características do modelo Heckscher-Ohlin-Samuelson (H-O-S), reafirmando ser de particular importância na determinação dos IDEs a dotação de recursos naturais de cada nação. A principal limitação do trabalho — assim como de toda a literatura baseada no modelo H-O-S - encontra-se em ex- 
plicar os motivos para a transnacionalização entre países com estruturas produtivas semelhantes ou ainda os movimentos do capital produtivo internacional de instalação de plantas em setores de alto conteúdo tecnológico em países periféricos.

Esta breve revisão da literatura evidencia a amplitude e diversidade das contribuições da literatura na explicação dos movimentos do capital produtivo. Não obstante sua importância, deve-se ressaltar que, de forma geral, ${ }^{2}$ esses trabalhos pretendem se constituir em teorias gerais dos movimentos do capital produtivo em nível internacional, as quais em sua grande maioria concedem pouca ou nenhuma importância ao contexto histórico específico no qual esses movimentos foram realizados.

A proposta de intrepretação de Possas (1983) sugere explicitamente que o entendimento dos movimentos do capital produtivo em direção a uma economia deve levar em consideração as condições internas e externas vigentes no período. Este trabalho faz uma leitura dos movimentos do capital produtivo em direção à economia brasileira durante seu processo de industrialização a partir dessa proposta de análise, ou seja, buscando explicar a inserção do capital estrangeiro produtivo na economia brasileira a partir de suas condições específicas e do contexto internacional vigente no período. Busca-se, dessa forma, demonstrar que o entendimento desse processo deve levar em consideração a dinâmica interna da economia e as condições vigentes no cenário econômico internacional.

\section{PROCESSO DE INDUSTRIALIZAÇÃO BRASILEIRO: UMA PERIOdIZAÇÃO}

O objetivo central deste trabalho é analisar a evolução do IDE durante o processo de industrialização brasileiro. Existem diversas interpretações sobre as origens e o desenvolvimento das atividades industriais no país. A complexidade e amplitude do tema em si encontram-se além dos objetivos específicos deste trabalho. Não obstante, apresentam-se algumas considerações de caráter introdutório ao tema.

De acordo com Suzigan (1986), existem quatro interpretações essenciais sobre as origens e o processo de industrialização brasileiro:

(1) a teoria dos choques adversos;

(2) a ótica da industrialização liderada pela expansão das exportações; 
(3) a interpretação baseada no desenvolvimento do capitalismo no Brasil (ou o "capitalismo tardio"); e

(4) a ótica da industrialização promovida por políticas de governo.

A primeira interpretação argumenta que o processo de industrialização brasileiro foi essencialmente derivado das respostas da economia local às dificuldades impostas pela Primeira Guerra Mundial e pela depressão dos anos 1930 no que se refere à redução das importações. Portanto, de acordo com essa interpretação, as limitações impostas pelos choques externos teriam estimulado o desenvolvimento da indústria local.

A segunda interpretação salienta o papel da expansão da economia agroexportadora cafeeira como elemento vital para o surgimento e o desenvolvimento das atividades industriais no país. O excedente gerado pela atividade agroexportadora - e que não poderia ser reinvestido no próprio setor - encontrava nas atividades industriais uma área de inversão, particularmente nos períodos de alta dos preços internacionais do café e de elevação da acumulação de capital dessa atividade.

A terceira vertente - o "capitalismo tardio" - destaca o papel retardatário do processo de industrialização no país como elemento central para o seu entendimento. A origem das atividades industriais encontra-se atrelada, de acordo com essa interpretação, à expansão das atividades agroexportadoras do café. Nesse sentido, a acumulação de capital do setor agroexportador e a impossibilidade de inversão desses recursos na própria atividade são vistas como essenciais para a expansão das atividades industriais. No entanto, a relação entre o desenvolvimento da indústria e a expansão do setor cafeeiro não é linear, tal como proposto pela segunda vertente. O contexto histórico específico do processo de industrialização brasileiro, retardatário em relação aos processos originais, impõe limites e particularidades que tornam a relação entre a expansão do setor exportador e o desenvolvimento da indústria mais complexa. Ao mesmo tempo em que os recursos da expansão cafeeira são considerados essenciais para o desenvolvimento da indústria, a capacidade de importação vinculada diretamente ao setor cafeeiro impõe limitações à expansão dessas atividades industriais.

Por fim a quarta vertente, de acordo com Suzigan (1986), destaca o papel exercido pelas políticas de governo, particularmente o papel desempenhado pela proteção tarifária e da concessão de incentivos e subsídios, como elemento central para o desenvolvimento das atividades industriais no país. 
Este artigo segue a proposta de periodização do processo de industrialização brasileiro baseada no desenvolvimento do capitalismo no Brasil (ou o "capitalismo tardio"), elaborada, entre outros, por Tavares (1975) e Mello (1982), na qual se destacam três momentos distintos:

(1) a fase do crescimento com diversificação da atividade industrial (1860-1933);

(2) a industrialização restringida (1933-1955); e

(3) a industrialização pesada (1955-1980). ${ }^{3}$

O período compreendido entre 1860 e 1933 assiste ao rápido crescimento das atividades industriais, particularmente concentradas nos setores de bens de consumo não-duráveis e com reduzida importância das atividades ligadas à produção de bens de capital e bens intermediários. Segundo Tavares (1975) e Mello (1982), nessa fase, o crescimento das atividades industriais era incapaz de endogeinizar o ritmo de crescimento da economia, ainda determinado pelos movimentos exógenos de contração/expansão do mercado internacional do café. Em outras palavras, o crescimento da atividade industrial no Brasil, acentuado no início do século XX, em função dos efeitos indiretos das políticas de manutenção da renda da economia cafeeira (Suzigan e Villela, 1975) e da acumulação previamente estabelecida no setor agroexportador (Mello, 1982), não pode ser considerado como determinante de um processo de industrialização. ${ }^{4}$

Somente a partir de 1933 deu-se, seguindo essa proposta de periodização, o início do processo de industrialização no Brasil, já que a partir desse ano o ritmo de crescimento da economia passou a ser determinado pelo ritmo de expansão do setor industrial. Verificou-se também um processo de diversificação da estrutura industrial, com aumento relativo dos setores produtores de bens de capital concomitantemente com a redução da importância relativa do setor de bens de consumo não-duráveis. ${ }^{5}$ Em outras palavras, a partir de 1933 o processo de acumulação de capital no interior da economia passou a se estruturar em um novo padrão. $\mathrm{O}$ ritmo de crescimento da economia não se encontrava mais vinculado à demanda externa, mas sim ao ritmo endógeno de acumulação de capital no setor industrial.

Porém, esse processo de diversificação da estrutura industrial era restrito, já que o crescimento da atividade industrial encontrava-se diretamente associado à capacidade de importação de bens de produção, que dependia 
das divisas obtidas pelo setor primário exportador. Assim, embora o ritmo de expansão da economia não esteja mais vinculado à demanda externa, os entraves impostos pela capacidade de importação, fortemente dependende do setor agroexportador, continuam a limitar a capacidade de crescimento da economia. Em suma, as crises de natureza cambial continuam a desempenhar papel fundamental como limitadoras do processo de desenvolvimento brasileiro durante o período de industrialização restringida. ${ }^{6}$

A partir de 1955, durante a execução do Plano de Metas, o caráter restrito do processo de industrialização foi superado, dando-se início à fase de “industrialização pesada” da economia brasileira. Esse momento é marcado pela realização de um bloco de investimentos concentrados, tanto em termos temporais (realizados em um curto período de tempo) quanto setoriais (particularmente nos setores de bens de produção) sob a liderança do estado e do capital privado internacional, ao qual o capital privado nacional associou-se de forma subordinada. A “industrialização pesada” é entendida, portanto, como uma nova fase do processo de industrialização que se distingue da precedente, tanto pelo tipo de investimento - que cresce à frente da demanda - quanto pelas características da estrutura técnica e financeira dos capitais. ${ }^{7}$

Na seqüência discute-se, a partir da periodização apresentada, o papel dos IDEs no processo de industrialização brasileiro. Argumenta-se também, seguindo a proposta de interpretação apresentada por Possas (1983), que o entendimento do comportamento do capital produtivo estrangeiro deve ser feito a partir da observação das condições internas e externas de acumulação do capital.

\section{CRESCIMENTO COM DIVERSIFICAÇÃO DA ESTRUTURA INDUSTRIAL E O INVESTIMENTO DIRETO EXTERNO}

A partir desta seção inicia-se a discussão sobre o papel do IDE na industrialização brasileira. O longo período de crescimento com diversificação da estrutura industrial (1860-1933) é subdividido, para fins de análise do comportamento dos fluxos de capital produtivo no país, em três subperíodos: 1860-1902, 1902-1914 e 1914-1933.

No período compreendido entre 1860 e 1902, o padrão de inserção dos IDEs apresenta-se bem definido. Há uma clara predominância dos investi- 
mentos de origem inglesa em atividades de serviços ligadas ao setor agroexportador cafeeiro. De acordo com Castro (1979), nesse período os investimentos de origem inglesa responderam por $77,6 \%$ do total do IDE no Brasil. Os investimentos franceses representavam apenas 5,9\% do total, enquanto a participação norte-americana não chegava a $2 \%$. A concentração nas atividades de serviços e a reduzida importância das atividades industriais também são patentes. O setor de serviços básicos ${ }^{8}$ respondia por $59 \%$ dos IDEs, enquanto a indústria de transformação respondia por apenas $4 \%$ do total desses investimentos. ${ }^{9}$

Embora as informações contábeis sobre os fluxos de IDE para o período sejam escassas, pode-se argumentar que entre 1860 e 1902 a economia brasileira não se constituiu em uma receptora importante de inversões estrangeiras de uma perspectiva global. A importância do Brasil como destino dos investimentos ingleses nesse longo período foi marginal. Em grande medida, isso se deve à concentração das inversões inglesas em suas áreas coloniais. Dados da ONU (1965) informam que entre 1860-1970 essas colônias receberam 36\% dos IDEs, restando 27 e 25\%, respectivamente, para os EUA e Europa, e apenas 10,5\% para a América Latina.

De uma forma geral, pode-se afirmar, seguindo os argumentos apresentados por Castro (1979) e Possas (1983), que as características apresentadas pelo IDE no Brasil refletem as condições internas e externas de acumulação. A predominância dos investimentos de origem inglesa reflete sua hegemonia no plano internacional, enquanto a concentração em atividades de serviços reflete a importância relativa do setor cafeeiro na economia brasileira. A reduzida importância relativa do Brasil na absorção de IDE, em particular de origem inglesa, pode ser entendida como derivada da concentração dos interesses britânicos em áreas coloniais.

A partir de 1902, mais precisamente no período que se estende entre esse ano e 1914, apresenta-se, segundo Castro (1979), uma importante alteração no padrão de inserção do IDE no Brasil. A participação norte-americana e canadense, até então desprezível, torna-se relevante. Paralelamente, assistese à redução da importância do capital de origem inglesa. Entre 1902-1914 os investimentos ingleses responderam por $53 \%$ dos IDEs, enquanto os investimentos norte-americanos e canadenses ${ }^{10}$ responderam por 19 e $11,1 \%$, respectivamente. 
Do ponto de vista da alocação dos investimentos, permanece a predominância das atividades de serviços básicos ligados ao setor agroexportador cafeeiro, responsáveis, nesse período, por $61,7 \%$ do total dos IDEs, enquanto a indústria de transformação respondeu por 7,2\% desse total. Em relação ao período anterior (1860-1902), nota-se um crescimento da participação da indústria de transformação no total dos IDEs que reflete, em alguma medida, o crescimento das atividades industriais no país. Porém, do ponto de vista relativo, o elemento que merece ser destacado é a manutenção da concentração setorial desses investimentos em atividades não manufatureiras.

Essas informações sobre a origem da propriedade do capital e suas áreas de concentração refletiam claramente o padrão de acumulação ${ }^{11}$ da economia brasileira e da economia internacional, tal como proposto por Possas (1983). No plano externo, seguindo Triffin (1979) e Block (1987), destaca-se a especificidade da estrutura do Balanço de Pagamentos da Inglaterra, então nação hegemônica, que garantia a manutenção da liquidez internacional e viabilizava os fluxos de bens e mercadorias.

A Inglaterra caracterizou-se nesse período como grande exportadora de capital (produtivo e de empréstimo), fruto de seus superávits em transações correntes, oriundos dos superávits na Balança de Serviços, com destaque para a conta de juros, apesar da crescente elevação dos déficits na Balança Comercial.

Esses elementos tornavam evidentes, segundo Block (1987), a perda de competitividade do setor produtivo inglês e o aumento do caráter financeiro da hegemonia inglesa nos últimos decênios do século XIX. Para se ter uma idéia dessa perda de importância do setor inglês no contexto internacional, lembra-se que em 1870 cerca de $31,8 \%$ da produção mundial encontravam-se sob o domínio de empresas inglesas, enquanto em 1914 esta não passava de 14\%. Concomitantemente, segundo Singer (1985), verificou-se o aumento da importância da produção industrial norte-americana e alemã.

O contexto internacional do período pode ser resumido como uma fase de acirramento da competição com a emergência dos sistemas industriais norte-americanos e alemão e a paralela perda de importância britânica na economia, em particular no que se refere à produção industrial.

No que tange às condições internas de acumulação, destaca-se o movimento de expansão da cultura cafeeira como eixo dinâmico do sistema eco- 
nômico, e cujo mercado consumidor, sobretudo o mercado externo, encontrava-se em franca expansão.

Sugere-se que a centralização dos investimentos estrangeiros, sobretudo ingleses, no setor de serviços básicos deve-se às possibilidades de investimento abertas pela expansão da cultura cafeeira. Explica-se também o crescimento da importância no setor ferroviário, fundamental no transporte do café das regiões produtoras para os portos, além do significativo crescimento dos investimentos nas atividades de importação e exportação. O mesmo argumento serve para a expansão dos investimentos em atividades portuárias, dado o caráter exportador da cultura cafeeira.

O caso americano confirma a hipótese de pouca importância do país como destino dos IDEs. Dados da ONU (1965) apontam que, de um total de US\$ 1,3 bilhão investido pelos EUA na América Latina, aproximadamente US\$ 1,0 bilhão encontrava-se em apenas três países: Cuba, com US\$252,6 milhões aplicados, sobretudo, na agroindústria açucareira; México, com US\$ 587,1 milhões; e Chile, com US\$170,8 milhões aplicados, sobretudo, no setor de mineração desses países. Castro (1979) estima em US\$ 38 milhões os IDEs americanos no Brasil entre 1902 e 1914.

Em suma, a análise do padrão de inserção dos capitais produtivos na economia brasileira no período que se estende de 1860 a 1914 permite afirmar que os movimentos do capital produtivo internacional reforçaram o caráter primário-exportador da inserção da economia no cenário internacional. Os grandes avanços técnicos do período e a conformação de setores industriais, como a indústria química básica, a indústria mecânica e de material elétrico, passaram completamente à margem da economia brasileira, ainda predominantemente direcionada às atividades agroexportadoras, caráter este que o capital estrangeiro direto apenas reforçou.

A preponderância dos investimentos ingleses, ainda que tendencialmente declinante, e a centralização em setores não manufatureiros dos IDEs devem ser entendidas como fruto das possibilidades internamente abertas ao investimento estrangeiro — atreladas à dinâmica da economia agroexportadora - e do movimento de acirramento da competição internacional, com destaque para a perda da hegemonia inglesa no cenário internacional, sobretudo no plano produtivo. Essas tendências foram mantidas - e até certo ponto acirradas — durante o período compreendido entre 1914-1933. 
Em primeiro lugar, nota-se a elevação da participação de investimentos de origem norte-americana na economia brasileira. De acordo com dados da ONU (1965), no ano 1928 os investimentos norte-americanos no país totalizaram US\$ 108 milhões. Esse aumento, no entanto, não alterou o papel secundário do Brasil como receptor desses investimentos. No mesmo ano, os IDEs de origem norte-americana atingiram US\$ 887,0 milhões em Cuba, US\$ 709,0 milhões no México e US\$ 448,0 milhões no Chile. A ampliação da importância dos IDEs de origem norte-americana explica, em grande medida, a elevação da importância dos setores industriais na recepção de investimentos estrangeiros no país. Em 1929, do estoque total de IDEs norte-americanos no Brasil, 50\% destinavam-se ao ramo de serviços públicos, 23,7\% a atividades industriais, $11,8 \%$ ao petróleo, $8 \%$ a atividades comerciais e $6 \%$ a outras atividades. ${ }^{12}$

A importância dos IDEs de origem norte-americana em atividades industriais contrasta claramente com o padrão de inserção dos investimentos ingleses e com o padrão de inserção dos investimentos norte-americanos em outros países. Em 1929, do total de investimentos norte-americanos na América Latina, 23,6\% destinavam-se ao setor agrícola, 21,1\% à mineração, 17,8\% à exploração de petróleo, 25,6\% ao setor ferroviário e apenas 6,7\% às atividades manufatureiras.

A particularidade da inserção dos IDEs norte-americanos no Brasil pode ser explicada por alguns fatores. De acordo com Singer (1985), duas hipóteses podem ser levantadas. Em primeiro lugar, certas áreas de investimento já se encontravam dominadas por investimentos de origem inglesa. Além disso, os norte-americanos teriam reproduzido nos demais países da América Latina o mesmo padrão de concentração setorial de investimentos que ingleses, franceses e alemães desenvolviam em suas colônias. A esses argumentos acrescenta-se que as oportunidades de inversão no Brasil eram distintas das existentes em outros países. Em particular, como apresentam Suzigan e Villela (1975), já existia no país, entre 1914 e 1933, um rápido crescimento das atividades industriais ligadas à produção de bens de consumo não-duráveis, elemento que não se apresentava de forma tão intensa nos países que concentravam os investimentos norte-americanos na América Latina.

Dessa forma, o período compreendido entre 1914 e 1933 deve ser entendido como uma fase de continuidade e acirramento das tendências previamente esboçadas de elevação da participação norte-americana com am- 
pliação paulatina da importância dos setores industriais na recepção de IDE. A continuidade desse processo revela a ampliação da importância norte-americana no cenário internacional (concomitantemente à redução da importância inglesa) e as oportunidades abertas internamente pelo desenvolvimento das atividades industriais, sobretudo ligadas à produção de bens de consumo não-duráveis, na economia brasileira.

Durante a análise do período compreendido entre 1860 e 1933 foi argumentado que o IDE exerceu um papel secundário no processo de crescimento com diversificação da matriz industrial. Essa conclusão encontra subsídio em dois elementos: o volume escasso de inversões estrangeiras no período e sua concentração setorial em atividades não manufatureiras.

No entanto, embora escassos e setorialmente concentrados em atividades não manufatureiras, os IDEs desempenharam um papel relevante em alguns ramos industriais. Suzigan e Szmrecsányi (1994) apresentam uma lista de atividades industriais nas quais o IDE desempenhou um papel importante, com destaque para:

- Processamento de Carnes: as quatro principais empresas internacionais do setor (Armour, Swift, Wilson e Frigorífico Anglo) detinham em, meados da década de 1930, aproximadamente $95 \%$ da capacidade nacional de abate e processamento de gado bovino e $87 \%$ da de suínos e bovinos.

- Fósforos: estima-se que, em 1907, três fábricas sob o controle do capital estrangeiro já respondiam por dois terços da produção nacional.

- Lâmpadas Elétricas: em 1927, cerca de 35\% do consumo total do produto no Brasil eram supridos pela General Electric.

- Cimento: duas fábricas estrangeiras controlavam, em 1935, cerca de três quartos do consumo aparente de cimento no Brasil.

Além desses dados, destaca-se também, em particular a partir de 1914, a importância dos IDEs em outras atividades, como apontam Queiroz e Evans (1977):

Por volta dos fins da Primeira Guerra Mundial... aumentava o ritmo do ingresso de capitais estrangeiros. A Ford e a General Motors seguiam a trilha das maiores companhias de petróleo, instalando organizações para lidar com a distribuição de seus carros. A Dupont, a Imperial Chemical Industries e a Remington participavam da fabricação de cartuchos e pólvora. A Pirelli começou fazendo cabos de cobre. A Phillips principiou construir rádios, e a Unilever instalou uma subsidiária brasileira para fabricar sabonetes. 
Essas informações não invalidam o argumento de que o capital estrangeiro desempenhou papel secundário na instalação da indústria brasileira até a década de 1930. Isso porque, além de seus investimentos serem escassos e de sua concentração setorial priorizar atividades não manufatureiras, o capital estrangeiro não desempenhou papel relevante nos setores mais dinâmicos da fase de crescimento com diversificação da estrutura industrial, os setores de bens de consumo não-duráveis. De acordo com Queiroz e Evans (1977), a indústria têxtil, por exemplo, setor-chave desse processo, absorveu, até 1914 , apenas $2,3 \%$ do total desses investimentos, sendo a participação do capital estrangeiro na produção local praticamente desprezível.

\section{INDUSTRIALIZAÇÃO RESTRINGIDA E O IDE}

O período compreendido entre 1933 e 1955 assiste a um intenso processo de crescimento das atividades industriais no Brasil. Chama a atenção, no entanto, como característica marcante desse período, o intenso processo de diversificação das atividades industriais, em que se destacam a redução da participação dos chamados setores de bens de consumo não-duráveis e o concomitante incremento de setores da indústria pesada. Alguns dados ilustram esse fenômeno. Em 1919, segundo Suzigan e Villela (1975), as indústrias têxteis, de vestuário e calçados, produtos alimentares, bebidas e fumo eram responsáveis por cerca de $70 \%$ do valor adicionado no setor industrial. O mesmo conjunto de setores respondia por 58\% desse valor em 1939.

$\mathrm{O}$ crescimento das atividades industriais, segundo Suzigan e Villela (1975), foi sobretudo relevante até o início da Segunda Guerra Mundial. A taxa de crescimento anual média do setor industrial durante o período compreendido entre 1933 e 1939 foi de 11,2\%, bastante superior à taxa anual de 5,4\% verificada para o período compreendido entre 1939 e 1945.

O contexto internacional do período que se estendeu de 1933 até o fim da Segunda Guerra Mundial foi marcado por extrema instabilidade, sobretudo no que se refere ao comportamento do mercado financeiro internacional e da retração do ritmo de crescimento da economia mundial. O período imediatamente posterior ao conflito marcou a consolidação da hegemonia norte-americana no plano internacional. Na esfera financeira, isso se tor- 
nou evidente a partir da instituição do acordo de Bretton Woods em 1944. $\mathrm{Na}$ esfera produtiva, segundo Dunning (1979), esse domínio tornou-se claro em função do processo de internacionalização da produção, que se deu sobre o domínio virtualmente exclusivo das grandes empresas norteamericanas.

O crescimento das atividades industriais com diversificação da estrutura produtiva, no plano doméstico, a consolidação da hegemonia norte-americana, no plano internacional, são elementos que merecem destaque para o período. O que dizer dos IDEs nesse período?

No que se refere especificamente à América Latina, notaram-se um reforço da tendência, já anteriormente vislumbrada, de aumento da participação dos investimentos de origem norte-americana e a concomitante redução dos investimentos de origem britânica. Dados da ONU (1965) apontam para um crescimento de 28,4\% nos IDEs norte-americanos entre 1929 e 1950, o que contrasta com a performance britânica de redução de $60 \%$ nos investimentos nesse período.

Cabe ressaltar que o período entre 1930 e1945, no qual Getúlio Vargas manteve-se na presidência, foi marcado pelo nacionalismo, com ênfase nos recursos naturais do país, vinculado a um processo de nação industrial que vinha sendo gestado por intelectuais e empresários nacionais, com a simpatia de Vargas, conforme apontado por Fonseca (1987). Contudo, esses interesses eram convergentes, com a atração de investimentos estrangeiros:

O nacionalismo de Vargas jamais significou, durante este período, qualquer restrição ao capital estrangeiro (afora a nacionalização das riquezas minerais)(...) Mesmo que a época não fosse de liquidez e de condições propícias ao investimento, Vargas não descartava a possibilidade de atrair capitais externos que viessem somar esforços para o desenvolvimento, mesmo que estes desejassem garantias e compensações (Fonseca, 1987, p. 218 e 219).

Conforme discurso do presidente Vargas, citado por Fonseca (1987, p. 219):

A míngua de recursos, própria dos países novos, pode ser corrigida não só por esse meio [estímulos governamentais], como pela atração de capitais estrangeiros que, confiantes em garantias e compensações, venham espontaneamente incorporar-se à nossa economia. 
Logo, o discurso de Vargas representa a disposição e o interesse político do governo brasileiro em propiciar as condições necessárias para a atração do investimento estrangeiro direto, em um momento caracterizado por uma forte transição política e econômica no cenário internacional e marcado pela ascensão da economia norte-americana. Contudo, em função da instabilidade política e econômica entre a crise de 1930 e a Segunda Guerra Mundial, o cenário internacional se torna mais favorável à expansão dos IDEs a partir da década de 1950.

Ainda assim, ao aumento das inversões estrangeiras, especialmente norte-americanas, no Brasil, em particular entre 1943 e 1950, soma-se uma mudança qualitativa importante anotada por Possas (1983). Particularmente após 1937, nota-se um aumento relativo no número de subsidiárias estrangeiras no Brasil, destacando-se o aumento da importância dos investimentos nos seguintes setores: produtos metálicos, minerais não metálicos (cimento e vidro), papel, equipamentos e aparelhos elétricos e tecidos sintéticos, além da indústria química em geral, que passam a se constituir em pólos de atração dos investimentos externos, demonstrando que os interesses estrangeiros no país haviam definitivamente ultrapassado os limites das atividades extrativas e mercantis.

No entanto, parece existir um relativo consenso na literatura que investiga o tema, com destaque para Singer (1985), Suzigan e Villela (1975) e Paiva Abreu (1984), de que o IDE desempenhou papel secundário nessa fase do processo de industrialização, sobretudo em comparação com o papel exercido pelo estado e pelo capital privado de origem nacional. Alguns argumentos podem ser destacados a favor dessa visão.

O primeiro analisa a concentração setorial dos IDEs no período. De acordo com Singer (1985) e Queiroz e Evans (1977), os ramos industriais em que já se configurava uma participação importante do capital estrangeiro no total da oferta nacional durante os anos 1930 e 1940 foram: a indústria farmacêutica, o cimento, alguns ramos da química e, principalmente, borracha e siderurgia, ou seja, os setores (com exceção da farmacêutica) produtores de bens intermediários. Mas qual a importância desses setores no processo de industrialização restringida? Segundo Singer (1985, p. 217): 
O peso específico destes ramos no conjunto da produção era ainda muito pequeno no fim da década de 1930 (...) ao valor adicionado na indústria de tranformação, em 1939 a indústria de borracha contribuía com somente $0,4 \%(\ldots)$ a de minerais não metálicos com $4,3 \%$ e a metalurgia com $7,6 \%$ (...) Trata-se do surgimento de um germe de indústria de base, cujo desenvolvimento se dará plenamente a partir do período seguinte (1956-67). $\mathrm{Na}$ verdade, o que caracteriza a industrialização deste período é a grande expansão da fiação e tecelagem e de outros ramos do DII, sobretudo dos que produziam bens de consumo não duráveis (exceto mobiliário).

Assim, de acordo com Singer (1985) e Paiva Abreu (1984), as atividades em que o capital estrangeiro concentrou seus investimentos não se constituíram no eixo central do processo de industrialização restringida, quer seja os setores de bens de consumo não-duráveis, amplamente dominados pelo capital privado nacional. Outro aspecto destacado pela literatura é que, muito embora o crescimento dos fluxos de IDE em atividades industriais seja inegável para o período, em particular para o período compreendido entre 1943 e 1950, seus montantes ainda eram insuficientes para mudar o padrão dos estoques de IDE no país. Dados do Banco Central do Brasil deixam claro esse ponto. Em 1950, 27,1\% dos estoques de IDE no país encontravam-se na atividade de energia elétrica. O setor de petróleo, com 12,9\%, e bancos, com 6,9\%, aparecem à frente do setor industrial com maior aporte de capital estrangeiro em 1950.

Em suma, assiste-se, no período de industrialização restringida, a um crescimento na importância dos IDEs na indústria brasileira. Em grande medida, isso é fruto das oportunidades abertas pelo rápido crescimento das atividades industriais no país e do paulatino deslocamento das atividades dinâmicas do setor agroexportador para a indústria. Esse fenômeno também reflete a conjuntura internacional, em que se destaca a consolidação da hegemonia norte-americana no plano internacional. Não obstante, as informações disponíveis permitem afirmar que o IDE desempenhou papel secundário nessa fase do processo de industrialização brasileiro comparativamente à importância do capital privado e estatal de origem nacional. Ainda assim, merece destaque o fato de que alguns dos mais importantes elementos que irão caracterizar o IDEs no período seguinte, a industrialização pesada, com destaque para o papel dos IDE norte-americanos na indústria pesada, já se encontravam presentes nessa fase da industrialização brasileira. 


\section{IDE E INDUSTRIALIZAÇÃO PESADA}

O IDE desempenhou papel fundamental no processo de industrialização pesada da economia brasileira. A primeira evidência em favor desse argumento encontra-se na observação do volume de capital IDE no país. Até o ano 1950, o estoque de IDE havia chegado a aproximadamente US\$ $334 \mathrm{mi}$ lhões. No decênio seguinte, ou seja, de 1951 a 1960, os fluxos de IDE atingiram aproximadamente US\$1,1 bilhão. Assim, em um período de apenas 10 anos após 1950, o volume de IDE mais do que triplicou em relação a todo o estoque de IDE anterior. Por um lado, essa informação confirma o caráter marginal da economia na recepção de IDE até 1950; por outro lado, permite configurar esse período como o primeiro boom do capital estrangeiro em sua forma produtiva na economia brasileira. Na década de 1960, esse processo é mantido. Entre 1961 e 1970, os fluxos de IDE atingiram US\$ 2,48 bilhões, evidenciando uma elevação de $124 \%$ em relação ao período anterior. ${ }^{13} \mathrm{Na}$ década de 1970, o crescimento nos fluxos de IDE para o país é considerável, de tal forma que seu estoque total atinge, em 1979, de acordo com dados do Banco Central do Brasil, a cifra de US\$ 9,6 bilhões.

Não é apenas a elevação dos fluxos de IDE para a economia que dá sustentação à afirmação inicial desta seção. Tão relevante quanto essa elevação dos investimentos estrangeiros é a análise de sua concentração setorial. O quadro 1 apresenta as informações necessárias para essa análise.

As evidências apresentadas no quadro 1 confirmam a centralização dos IDEs em atividades industriais no período analisado. Do estoque total de IDEs em 1979, aproximadamente 77,3\% encontravam-se em atividades da indústria de transformação. A indústria extrativa mineral, os serviços de utilidade pública e a agricultura representavam, respectivamente, 2,3\%, $0,2 \%$ e $0,5 \%$.

Mais interessante ainda é notar a concentração desses investimentos em setores dinâmicos do paradigma tecnológico metalmecânico-químico e nas chamadas commodities industriais vis-à-vis os setores tradicionais. ${ }^{14}$

O processo de industrialização pesada da economia brasileira contou, portanto, com um novo padrão de inserção do capital produtivo internacional, caracterizado pela concentração de investimentos em atividades industriais, em particular naquelas que se constituem no eixo dinâmico do para- 
Quadro 1: Participação dos 10 principais setores no total dos estoques dos IDEs no Brasil (1950, 1960 e 1970)*

\begin{tabular}{|c|}
\hline Energia elétrica: $27,1 \%$ \\
\hline Petróleo: $12,9 \%$ \\
\hline Bancos: 6,9\% \\
\hline Produtos químicos: $5,9 \%$ \\
\hline Alimentos: 5,6\% \\
\hline Aparelhos eletrônicos: 4,9\% \\
\hline Indústria automobilística: 3,2\% \\
\hline Metalurgia: $2,4 \%$ \\
\hline Cimento: $2,3 \%$ \\
\hline Farmacêuticos: 1,5\% \\
\hline 1970 \\
\hline Indústria automobilística: 11,5\% \\
\hline Produtos químicos básicos: $10,9 \%$ \\
\hline Petróleo: $6 \%$ \\
\hline Aparelhos eletrônicos: 5,9\% \\
\hline Metalurgia: 5,5\% \\
\hline Farmacêuticos: 4,8\% \\
\hline Serviços liberais: $4,6 \%$ \\
\hline Energia elétrica: 4,4\% \\
\hline Alimentos: $3,7 \%$ \\
\hline
\end{tabular}

1960

Indústria automobilística: 11,4\%

Petróleo: $11 \%$

Produtos químicos: 10,8\%

Metalurgia: 5,4\%

Alimentos: $5 \%$

Farmacêuticos: 4,5\%

Aparelhos eletrônicos: 4,3\%

Siderurgia: 3,6\%

Atividades comerciais: 3,3\%

Autopeças: 2,8\%

1979

Produtos químicos básicos: 11,38\%

Mecânica: 10,41\%

Material elétrico e comunicação: 8,79\%

Metalurgia: 8,67\%

Veículos automotores: 8,5\%

Produtos medicinais, farmacêuticos e veterinários:

$4,01 \%$

Autopeças: 3,1\%

Indústria extrativa mineral: $2,8 \%$

Siderurgia: 2,7\%

Produtos alimentares: $2,6 \%$

Fonte: Boletim do Banco Central do Brasil - Separata de dezembro de 1979. Elaboração própria.

digma tecnológico metalmecânico-químico. A importância do IDE na consolidação do processo de industrialização pesada da economia brasileira é amplamente reconhecida. Diversos autores, com destaque para Serra (1982), Queiroz e Evans (1977) e Tavares (1975), concluem que sem a participação desses investimentos o processo de industrialização pesada da economia brasileira seria inviável.

A análise da origem de propriedade desses capitais revela, entre outros elementos, a predominância dos investimentos de origem norte-americana nesse processo. A tabela 1 apresenta as informações necessárias para uma discussão mais detalhada sobre o tema. 
O primeiro ponto a ser destacado da observação da tabela 1 é a predominância dos IDEs de origem norte-americana. Entre 1951 e 1960 os IDEs norte-americanos foram responsáveis por 37,15\% do total dos IDEs para o país. Outros elementos chamam a atenção, como a redução das participações inglesa - principal investidora na fase inicial do processo de industrialização - e canadense. Este último caso pode ser explicado pela perda da importância dos IDEs no setor de energia elétrica após 1950, tendo-se em conta que grande parte dos investimentos canadenses concentrava-se nesse setor, em especial através de investimentos da Light \& Power. Por fim, chamam a atenção também a participação elevada de investimentos suíços, em particular para o período entre 1951 e 1960, quando atingiram 14,29\% dos fluxos totais de IDE no país, e o crescimento significativo da participação alemã, particularmente entre 1961 e 1969, quando foram responsáveis por $17,51 \%$ dos fluxos de IDE.

A posição consolidada dos IDEs por país em 30.6.1979 demonstra, de acordo com dados do Banco Central do Brasil, a manutenção das principais tendências verificadas no período anterior. $\mathrm{O}$ único destaque no período refere-se ao significativo incremento da importância japonesa nos IDEs ao longo da década de 1970.

Neste ponto, uma indagação torna-se essencial: quais os elementos que explicam a mudança da inserção do capital produtivo internacional na economia brasileira na sua fase de industrialização pesada? Seguindo o argu-

Tabela 1: Investimentos externos no Brasil, origem de propriedade do capital* em (\%)

\begin{tabular}{lcccc}
\hline País & Até $1950 *$ & $1951-1960$ & $1961-1969$ & Acumulado até 1979 \\
\hline EUA & 29,25 & 37,15 & 27,89 & 28,00 \\
\hline Canadá & 28,8 & 5,8 & 5,6 & 4,00 \\
\hline Reino Unido & 11,08 & 6,6 & 4,34 & 5,70 \\
\hline Suiça & 7,8 & 14,29 & 11,12 & 11,60 \\
\hline Itália & 2,6 & 0,5 & 3,4 & 1,50 \\
\hline França & 2,2 & 4,13 & 5,05 & 4,20 \\
\hline Holanda & 1,5 & 1,7 & 4,43 & 2,10 \\
\hline Japão & 0,43 & 2,7 & 3 & 10,00 \\
\hline Alemanha & n.d & 13,08 & 17,51 & 15,10 \\
\hline Total do Grupo & 83,66 & 85,95 & 82,34 & 82,20 \\
\hline
\end{tabular}

Fonte: Separata do Banco Central do Brasil, dez. 1979. Elaboração própria.

* Até 1950: refere-se ao estoque, assim como o acumulado até 1979. As informações relativas aos períodos 1951-1960 e 1961-1969 referem-se aos fluxos. 
Tabela 2: Estimativas de PNB real per capita para uma seleção de países (em US\$ de 1960)

\begin{tabular}{lcccccc}
\hline Países & 1860 & 1913 & 1929 & 1950 & 1960 & 1970 \\
\hline Alemanha (Ocidental) & 345 & 775 & 900 & 995 & 1.790 & 2.705 \\
\hline Canadá & 405 & 1.110 & 1.220 & 1.785 & 2.205 & 3.005 \\
\hline Espanha & 325 & 400 & 520 & 430 & 640 & 1.400 \\
\hline Estados Unidos & 550 & 1.350 & 1.775 & 2.415 & 2.800 & 3.605 \\
\hline Holanda & 410 & 740 & 980 & 1.115 & 1.490 & 2.385 \\
\hline França & 380 & 670 & 890 & 1.055 & 1.500 & 2.535 \\
\hline Japão & 175 & 310 & 425 & 405 & 855 & 2.130 \\
\hline Portugal & 290 & 335 & 380 & 440 & 550 & 985 \\
\hline Reino Unido & 600 & 1.070 & 1.160 & 1.400 & 1.780 & 2.225 \\
\hline Rússia (União Soviética) & 200 & 345 & 350 & 600 & 925 & 1.640 \\
\hline
\end{tabular}

Fonte: Bairoch. Main trends in national economic disparites". In: Bairoch e Lévy-Leboyer (Orgs.). Disparities in economic development, p. 10, apud Landes (1998, p. 258).

mento desenvolvido até o momento, são as condições internas e externas de acumulação que devem ser analisadas para responder a essa questão.

No plano internacional, os anos 1950 e 1960 são conhecidos na literatura econômica como "décadas douradas do capitalismo". Esse período é caracterizado pelo intenso ritmo de crescimento da economia mundial, que ocorre de forma assimétrica em termos intra-regionais e tem no ritmo de crescimento industrial o "motor" do sistema. A tabela 2 demonstra o crescimento expressivo da renda per capita a partir de 1950, com destaque para os Estados Unidos, que já no início do século XX despontam com um PNB per capita estimado maior que o do Reino Unido.

Destaca-se, ainda, a consolidação do paradigma tecnológico metalmecânico-químico como base tecnológica do sistema industrial, com significativo realce para o ritmo de crescimento de alguns setores em particular, os de material de transporte e elétrico, a indústria mecânica, o complexo químico e o setor de metalurgia. Outro aspecto essencial da conjuntura internacional do imediato pós-guerra é a consolidação do papel hegemônico da economia norte-americana no cenário internacional, em suas esferas comercial, financeira, produtiva e militar.

As "décadas douradas" irão determinar outro importante fenômeno: a grande empresa em escala internacional passa a se constituir no elemento responsável pela dinâmica da economia internacional.

A análise, no entanto, deixa transparecer que o processo de internacionalização no imediato pós-guerra é genérico às "grandes empresas". Uma im- 
portante qualificação deve ser realizada. Esse processo, seguindo Dunning (1979), é restrito a um único agente — a grande empresa norte-americana. Em outras palavras, a internacionalização produtiva do imediato pós-guerra é a internacionalização de um sistema industrial específico: o sistema industrial hegemônico norte-americano. A tabela 3 fornece evidências da preponderância norte-americana.

A concentração setorial dos IDEs de origem norte-americana é outro elemento que deve ser analisado. Michalet (1984) apresenta evidências da tendência de concentração dos IDEs em setores da indústria manufatureira vis-à-vis outros setores, tais como a mineração e o petróleo. De acordo com o autor, em 1957 a principal área de concentração dos IDEs norte-americanos era a atividade petrolífera, que concentrava $35,60 \%$ do estoque total de IDE contra 31,4\% desse estoque em atividades ligadas à indústria manufatureira. Em 1971, o quadro já era diferente. A indústria manufatureira já se tornara a principal área de investimentos produtivos americanos, respondendo por $41,20 \%$ dos estoques contra $28,1 \%$ de atividade petrolíferas.

Dunning (1979) apresenta informações igualmente relevantes sobre a concentração setorial dos IDEs norte-americanos. De acordo com o autor, em 1975 os setores intensivos em tecnologia ${ }^{15}$ responderam por $67 \%$ dos IDEs norte-americanos, enquanto setores menos intensivos em tecnologia ${ }^{16}$ responderam por apenas $8,4 \%$ desse total.

Essas informações ajudam a entender — seguindo a proposta de interpretação de Possas (1983) - o comportamento do capital produtivo no Brasil. A predominância norte-americana é um fato incontestável no plano

Tabela 3: Estoque de investimento direto externo por país (1967)

\begin{tabular}{lcc}
\hline País de origem & US\$ milhões & $(\%)$ do IDE total \\
\hline Estados Unidos & 59.486 & 55,00 \\
\hline Reino Unido & 1.752 & 16,20 \\
\hline França & 6.001 & 5,50 \\
\hline Suíça & 4.251 & 3,90 \\
\hline Canadá & 3.728 & 3,40 \\
\hline Alemanha & 3.015 & 2,80 \\
\hline Holanda & 2.251 & 2,10 \\
\hline Itália & 2.111 & 1,90 \\
\hline Bélgica & 2.100 & 1,90 \\
\hline Suécia & 1.514 & 1,40 \\
\hline
\end{tabular}

Fonte: Michalet (1984). 
internacional, assim como no caso específico brasileiro. Da mesma forma, a concentração setorial dos IDEs na fase de industrialização pesada da economia brasileira em atividades da indústria manufatureira, em particular em setores dinâmicos do paradigma tecnológico metalmecânico-químico, não pode ser considerada uma especificidade do caso brasileiro, mais sim a regra de comportamento das inversões norte-americanas. Em suma, diversas características do padrão de inserção dos IDEs durante a fase de industrialização pesada da economia brasileira são, em última análise, o reflexo do processo de internacionalização da grande empresa norte-americana em escala global.

As condições vigentes na economia brasileira do período também fornecem informações relevantes para a compreensão do comportamento do capital produtivo. Vale lembrar que, a partir de 1955, o estado brasileiro iniciou um conjunto de inversões na economia. A superação do caráter restringido do processo de industrialização não se deu através da continuidade do processo de crescimento com diversificação da estrutura industrial. Em outras palavras, não se tratou de uma acentuação do processo precedente.

A implantação do setor de bens de produção não ocorreu como uma continuidade do processo de instalação dos setores de bens de consumo, mas sim através, tal como dito, de um bloco de investimentos concentrados em termos temporais e setoriais, a partir de um significativo esforço de investimento do estado brasileiro. No que compete ao papel desse agente, basta, em função dos objetivos deste trabalho, observar que foi o responsável pela instalação dos setores de bens intermediários e de insumos básicos, setores que se constituíam nos de maior volume de inversão inicial, maior prazo de maturação e menor taxa de rentabilidade, características que, por um lado, impossibilitavam a entrada do capital privado nacional — dadas as barreiras financeiras e tecnológicas impostas - e que, por outro, não estimulavam a inversão produtiva estrangeira. A concentração dos IDEs na indústria manufatureira, em particular em atividades dinâmicas do paradigma tecnológico metalmecânico-químico, refletia não apenas o padrão vigente do IDE em nível internacional - em particular das inversões de grandes empresas norte-americanas —, mas também as oportunidades de investimento abertas internamente a partir do amplo conjunto de investimentos do estado no período e da proteção à indústria local. 
Portanto, além de um cenário internacional bastante favorável à ampliação dos IDEs, liderados pelos interesses de expansão das grandes empresas norte-americanas, o Brasil apresentou-se como uma opção atrativa para o fluxo de IDEs; dentre outros motivos, no que diz respeito ao cenário doméstico, estava em curso um processo de industrialização no país, para o qual havia disposição e interesse político do governo brasileiro em propiciar as condições necessárias para a atração do investimento estrangeiro direto, conforme constatado através dos discursos do governo Vargas, analisados por Fonseca (1987).

Além disso, a política de estímulo à industrialização, fortemente amparada nos instrumentos de proteção à produção local, a qual estimulava os IDEs, teve também um papel importante da classe industrial brasileira, de acordo com Leopoldi (2000, p. 67):

O período imediatamente posterior à guerra foi de afirmação crescente da indústria na economia do país. Entendemos que isso não se explica apenas por fatores econômicos externos, como entende a historiografia econômica, mas se deve também à luta das associações industriais pela proteção tarifária. O papel das associações industriais, através do lobby ou da atuação direta em órgãos consultivos do governo, teve bastante importância na evolução da indústria nacional.

A utilização dos instrumentos que caracterizaram a política industrial nesse período, com destaque para as barreiras tarifárias e a taxa de câmbio, foi conduzida diante de intensos conflitos de interesses, que resultavam em freqüentes divergências entre o governo e alguns setores da indústria, de acordo com Leopoldi (2000). Contudo, esse processo demonstra um aspecto importante da economia política do país naquele momento, que provavelmente proporcionou parte do cenário doméstico atrativo ao capital estrangeiro.

Dessa forma, observa-se que a participação dos IDEs tem papel fundamental no processo de industrialização e diversificação da indústria brasileira, porém, não se trata de um processo mecânico que responde apenas ao mecanismo de preços relativos determinados pelas forças de mercado. O cenário internacional é caracterizado por um período pós-Segunda Guerra Mundial, do qual os Estados Unidos saem suficientemente fortalecidos política e economicamente, para conduzirem as negociações do acordo de 
Bretton Woods, elevando sua moeda à condição de base do funcionamento do sistema financeiro internacional. Portanto, o cenário macroeconômico proporcionado por um processo de coordenação política foi fundamental para que as grandes empresas norte-americanas tivessem condição favorável, com destaque para uma menor incerteza à expansão do capital produtivo para regiões com maior demanda reprimida. Por outro lado, a estratégia de desenvolvimento brasileira, baseada no processo caracterizado pela proteção do mercado doméstico e no investimento estatal em infra-estrutura e setores com longa maturidade do capital, proporcionava uma condição local bastante favorável à atração de investimentos estrangeiros diretos.

Por fim, cabe analisar a importância do capital estrangeiro na atividade produtiva no Brasil. A tabela 3 apresenta informações sobre a participação por origem de capital no total das vendas para o ano 1980. Pode ser observado que capital estrangeiro desempenhava papel predominante (acima de $50 \%$ das vendas) nas atividades de material de transporte, borracha, produtos farmacêuticos, perfumaria e sabões e fumo. Sua participação ainda era muito importante (acima de $40 \%$ das vendas) nos setores de metais não ferrosos, mecânica e material elétrico.

\section{CONSIDERAÇÕES FINAIS}

Este artigo procurou demonstrar que o entendimento dos movimentos do capital produtivo estrangeiro na economia brasileira deve levar em consideração as condições internas e externas de acumulação, como proposto originalmente por Possas (1983), separando a análise em três fases do processo de industrialização.

Observou-se nesses períodos uma clara diferenciação quanto ao volume dos investimentos, concentração setorial e origem de propriedade do capital, sendo esses os três enfoques tratados por este trabalho.

$\mathrm{Na}$ fase inicial do processo de industrialização brasileiro, caracterizado pelo "Crescimento com Diversificação da Atividade Industrial” (1860-1933), havia a hegemonia inglesa no direcionamento do fluxo de capitais. Nesse período, o volume dos IDEs no Brasil foi pouco expressivo, sendo a própria Inglaterra o principal emissor. Quanto à alocação setorial, houve uma intensificação dos IDEs em serviços básicos, de forma a estimular a atividade agrícola, principalmente agroexportadora, o que basicamente referendava a 
Tabela 4: Participação das empresas por origem de capital no total das vendas para 1980

\begin{tabular}{|c|c|c|c|}
\hline Gêneros & Nacionais privadas & Empresas estrangeiras & Empresas estatais \\
\hline Minerais não metálicos & 72 & 28 & 0 \\
\hline Ferro e aço & 37 & 23 & 40 \\
\hline Metais não ferrosos & 56 & 44 & 0 \\
\hline Produtos metálicos & 75 & 23 & 2 \\
\hline Mecânica & 59 & 41 & 0 \\
\hline Material elétrico & 56 & 44 & 0 \\
\hline Material de transportes & 29 & 68 & 3 \\
\hline Madeira & 95 & 5 & 0 \\
\hline Mobiliário & 97 & 3 & 0 \\
\hline Papel e celulose & 75 & 21 & 5 \\
\hline Borracha & 37 & 63 & 0 \\
\hline Couros e peles & 85 & 15 & 0 \\
\hline Produtos químicos & 27 & 21 & 52 \\
\hline Produtos farmacêuticos & 28 & 71 & 1 \\
\hline Perfumaria e sabões & 47 & 53 & 0 \\
\hline Plásticos & 83 & 17 & 0 \\
\hline Têxtil & 78 & 22 & 0 \\
\hline Vestuário e calçados & 96 & 4 & 0 \\
\hline Produtos alimentares & 81 & 18 & 1 \\
\hline Bebidas & 85 & 15 & 0 \\
\hline Fumo & 27 & 73 & 0 \\
\hline Editorial e gráfica & 91 & 3 & 6 \\
\hline
\end{tabular}

Fonte: BNDES, 1988.

divisão internacional do trabalho composta a partir das vantagens comparativas. Cabe ressaltar que internamente havia uma dinâmica de acumulação do capital por parte do setor agroexportador, que teria basicamente financiado o início desse processo.

$\mathrm{Na}$ fase seguinte, configurada como "Industrialização Restringida" (19331955), o volume dos IDEs passou a ser mais expressivo para o processo de formação da estrutura industrial brasileira. A partir da década de 1930, os EUA já se destacavam como principal investidor externo na economia brasileira, com uma mudança qualitativa no direcionamento desses investimentos. Além dos serviços públicos, alguns setores da indústria também passaram a receber capital sob a forma produtiva, com destaque para os produtos metálicos, minerais não metálicos, papel, equipamentos e aparelhos elétricos, indústria têxtil e química. 
Nesse período, a característica da inserção do capital produtivo demonstra fortes indícios de que o interesse estrangeiro no país havia ultrapassado os limites das atividades extrativas e mercantis. A forte presença dos EUA nesse processo já seria resultado de sua ascensão econômica e militar, a qual fica evidenciada após a Segunda Guerra Mundial.

Por fim, o período da "Industrialização Pesada" (1955-1980), no qual o IDE passou a ter papel fundamental, com um volume de recursos bastante expressivo que resultou no primeiro boom do capital estrangeiro em sua forma produtiva na economia brasileira. Além de maior expressão quanto ao volume, houve uma concentração desses recursos na indústria de transformação, em setores dinâmicos do paradigma tecnológico metalmecânicoquímico. Nessa ocasião, a predominância dos investimentos de origem norte-americana apresenta evidências de que a inserção dos IDEs no Brasil naquele momento era resultado, em grande medida, da própria dinâmica de expansão da indústria norte-americana, através de um processo de internacionalização.

Caberia destacar que essa expansão dos IDEs norte-americanos, especialmente estadunidenses, no Brasil, foi fruto, em grande medida, do acirramento do processo de competição entre as grandes empresas multinacionais, que se deu a partir do final dos anos 1950. Nesse sentido, o crescimento das inversões estadunidenses no Brasil, sobretudo a partir dos anos 1970, pode ser entendido como uma resposta dessas empresas ao movimento inicial de expansão das inversões européias, ocorridas especialmente durante o ciclo de expansão associado ao Plano de Metas. Finalmente, cabe ressaltar a existência de um cenário bastante favorável, após a Segunda Guerra Mundial, com o sistema financeiro internacional pautado no acordo de Bretton Woods, que tinha nos EUA o principal coordenador de um período reconhecido como "décadas douradas do capitalismo".

\section{NOTAS}

1. Para uma discussão mais detalhada sobre o tema, veja Cantwell (1990).

2. A principal exceção a essa crítica é a contribuição de Dunning (1979).

3. A escolha dessa interpretação específica não reduz a importância das vertentes acima discutidas. Trata-se somente de uma opção dos autores, que se justifica em função do papel essencial exercido pelo IDE no processo de industrialização, sobretudo a partir de 
1955. A utilização da periodização também não significa que ela não seja passível de críticas. Goldenstein (1994), por exemplo, sintetiza uma série de elementos críticos em relação à periodização proposta por essa vertente, sobretudo no que se refere à pouca importância dispensada às condições internacionais após a fase da industrialização pesada. Esse debate, ainda que importante, encontra-se além dos objetivos deste trabalho.

4. Isso não significa dizer que nessa fase (1860-1933) não existiam atividades industriais no país. O crescimento das atividades ligadas à indústria, sobretudo a partir da década de 1920, é um fenômeno discutido pela literatura. Possas (1983) e Suzigan (1986) apresentam evidências do crescimento das atividades industriais no país a partir de 1914, sobretudo da indústria de bens de consumo não duráveis. $\mathrm{O}$ argumento de Tavares (1975) e Mello (1982) não despreza esse fenômeno, apenas argumenta que esse crescimento das atividades industriais era incapaz de determinar o ritmo de crescimento econômico nesse período. Em outras palavras, o ritmo de expansão da economia brasileira encontrava-se ainda diretamente vinculado ao setor cafeeiro.

5. Em 1920, cerca de 75\% da produção industrial eram derivados do setor de bens de consumo não-duráveis, com participação significativa dos ramos têxteis, bebidas e produtos alimentares, enquanto o setor de bens de produção respondia por apenas $7 \%$ do produto industrial. Já em 1939, a produção dos setores de bens intermediários e bens de capital saltou respectivamente para $22 \%$ e $8,8 \%$ do produto industrial, de acordo com Possas (1983).

6. "Neste período de industrialização, pela primeira vez na história da economia brasileira se combinam dois fatores contraditórios, que permitem identificar uma nova dinâmica de crescimento. O primeiro é que o processo de expansão industrial comanda o movimento de acumulação de capital, em que o segmento urbano da renda é o determinante principal das condições de demanda efetiva, vale dizer da realização dos lucros. O segundo resulta de que o desenvolvimento das forças produtivas e os suportes internos da acumulação urbana são insuficientes para implantar a grande indústria de base necessária ao crescimento da capacidade produtiva adiante da própria demanda. Assim, a estrutura técnica e financeira do capital continua dando os limites endógenos de sua própria reprodução ampliada, dificultando a autodeterminação do processo de desenvolvimento" (Tavares, 1975, p. 118).

7. "Tanto o tipo de crescimento da capacidade produtiva, muito na frente da demanda preexistente, como o caráter concentrado do bloco de investimentos no tempo não parecem, em nada, com a etapa de industrialização do após Guerra. A estas características das escalas de produção agregue-se o fato de que os empresários nacionais careciam de instrumentos prévios de mobilização e centralização de capital, necessários a uma concentração de recursos internos e externos, da magnitude requerida. Por outro lado, a estrutura técnica e financeira dos novos capitais era também completamente diferente da anterior, e não se podia obter a partir da simples expansão e diversificação da estrutura produtiva existente" (Tavares, 1975, p. 132).

8. Na classificação de Castro (1979), o setor é composto pelas seguintes atividades: ferrovias, companhias de gás, iluminação e transportes, telefones e telégrafos, portos, companhias de navegação, obras públicas e serviços particulares. 
9. Para uma discussão mais aprofundada sobre a repartição dos investimentos no setor de "serviços básicos", incluindo as divergências relativas à origem de propriedade, veja-se Castro (1979).

10. Associados aos investimentos da Light \& Power, no setor de energia elétrica e iluminação.

11. O "padrão de acumulação", seguindo-se particularmente Tavares (1975), reflete as condições objetiva e historicamente determinadas de acumulação de capital da economia. O seu entendimento requer "a identificação das relações básicas entre a estrutura da produção e repartição da renda”. Objetivamente, até 1914 a acumulação de capital da economia encontrava-se diretamente associada aos resultados obtidos pelo setor cafeeiro. No entanto, para compreensão efetiva do padrão de acumulação é necessário levar em conta a estrutura fundiária brasileira e o elevado grau de concentração da renda. Dessa forma, a concentração dos IDEs em atividades de serviços básicos ligados ao setor agroexportador cafeeiro observada para o período é justificada pela predominância das atividades ligadas ao setor na acumulação de capital da economia.

12. Em grande medida, a concentração dos IDEs no ramo de serviços públicos deve-se ao peso dos investimentos da Ligth canadense, o que reforça a reduzida importância destacada dos investimentos diretos externos de origem estadunidense nesse período da industrialização brasileira.

13. Esses dados foram retirados da Separata do Boletim do Banco Central do Brasil de 1979. Os valores referem-se ao total dos investimentos e reinvestimentos estrangeiros na economia brasileira e as moedas encontram-se convertidas em US\$ às paridades vigentes em 30.6.1979.

14. Utiliza-se aqui a proposta de agregação setorial elaborada por Canuto (1994).

15. Química, mecânica, material elétrico e de transporte.

16. Alimentos, bebidas e fumo, têxtil, couro, vestuário e calçados, papel e artigos para impressão, produtos primários e fabricação de metais.

\section{REFERÊNCIAS BIBLIOGRÁFICAS}

BANCO CENTRAL DO BRASIL. Boletins do Banco Central do Brasil. Brasília, Diversos números.

BELLUZO, L. G. M.; COUTINHO, R. Desenvolvimento capitalista no Brasil: ensaios sobre a crise. 2 ed. São Paulo: Brasiliense, 1983.

BLOCK, F. Las Origines Del Desorden Econômico Internacional. 2.ed. México, DF: Fondo de Cultura, 1987.

BNDES. O capital estrangeiro na indústria brasileira: atualidade e perspectiva. Rio de Janeiro, 1988. (Texto para Discussão.)

CANTWELL J. A survey of theories of international production In: PITELIS, C.; SUGDEN, R. (Org.). The nature of the transnational firm. Londres: Routledge, 1990. 
CANUTO, O. Brasil e Coréia do Sul: os (des)caminhos da industrialização tardia. São Paulo: Nobel, 1994.

CASTRO, A. C. As empresas estrangeiras no Brasil (1860-1913). São Paulo: Zahar Editores, 1979.

COASE, R.H. The nature of firm. In: WILLIANSON, O. E.; MASTEN S. E. (Ed.).The Economic of Transation Cost. [s.l.]: Edward Elgar Publishing, UK, 1937.

DUNNING, J. H. Explaining changing patterns of international production: in defense of the ecletic theory. Oxford Bulletin of Economics and Statistics, v. 41, n. 4, nov. 1979.

FONSECA, P. C. D. Vargas: o capitalismo em construção (1906-1954). São Paulo: Brasiliense, 1987.

GOLDENSTEIN, L. Repensando a dependência. São Paulo: Paz e Terra, 1994.

HENNART, J. F. The transnational cost theory of the multinational enterprise. In: PITELIS, C.; SUGDEN, R. (Org.). The nature of the transnational firm. Londres: Routledge, 1990.

HYMER, S. International operations of national firms. A study of direct investiment. [s.l.]: PHD Thesis, MIT, 1976.

KOJIMA, K.; OSAWA, T. Toward a theory of industrial restructuring and dynamic comparative advantage. Hitotsubashi Journal of Economics, n. 26, dez. 1985.

LANDES, D. A riqueza e a pobreza das nações. Rio de Janeiro: Campus, 1998.

LAPLANE, M.; SARTI, F. Investimento direto estrangeiro e o impacto na balança comercial nos anos 90. Texto para Discussão, Brasília: IPEA, n. 629, fev. 1999.

LEOPOLDI, M. A. P. Política e interesses na industrialização brasileira: as associações industriais, a política econômica e o estado. São Paulo: Paz e Terra, 2000.

MELlO, J. M. C. de. O capitalismo tardio. São Paulo: Brasiliense, 1982.

MICHALET, C. A. O capitalismo mundial. São Paulo: Paz e Terra, 1984.

ONU. External Financing in Latin America. Nova York: comissão econômica para a América Latina e o Caribe. Organização das Nações Unidas, 1965.

PAIVA ABREU, M. Notas sobre algumas fontes primárias estrangeiras para a história econômica brasileira. Rio de Janeiro: PUC/RJ, 1984.

POSSAS, M. L. Multinacionais e industrialização no Brasil. In: BELLUZO, L. G. M.; COUTINHO, R. Desenvolvimento capitalista no Brasil: ensaios sobre a crise. 2. ed. São Paulo: Brasiliense, 1983.

QUEIROZ, M. V.; EVANS, P. B. Um delicado equilíbrio: o capital internacional e o local na industrialização brasileira. In: QUEIROZ et al. Multinacionais: internacionalização e crise. Sao Paulo: Brasiliense, 1977.

SERRA, J. Ciclos e mudanças estruturais na economia brasileira. In: BELLUZO, L. G. (Org.). Desenvolvimento capitalista no Brasil: ensaios sobre a crise. São Paulo: Brasiliense, 1982.

SINGER, P. O Brasil no contexto do capitalismo internacional (1889-1930). História Geral da Civilização Brasileira, v. III, 1985. 
SUZIGAN, W. Indústria brasileira: origem e desenvolvimento. São Paulo: Brasiliense, 1986.

; SZMRECSÁNYI, T. Os investimentos estrangeiros no início do processo de industrialização no Brasil. Texto para Discussão, IE/Unicamp, n. 33, 1994.

; VILLELA, A. Política de governo e crescimento da economia brasileira. Rio de Janeiro: IPEA, 1975.

TAVARES, M. C. Acumulação de capital e industrialização no Brasil. (Tese de Livre Docência) - Universidade Federal do Rio de Janeiro, Rio de Janeiro, 1975.

TRIFFIN, R. A evolução do sistema monetário internacional: reavaliação histórica e perspectivas futuras. 1979. Série Anpec.

VERNON, R. International investiment and international trade in the product cycle. Quartely Journal of Economics. Cambridge, maio 1966. 
